\title{
Does watching a monkey change its behaviour? Quantifying observer effects in habituated wild primates using automated radiotelemetry
}

\author{
Margaret C. Crofoot ${ }^{\text {a,b,c,*}, ~ T h o m a s ~ D . ~ L a m b e r t ~}{ }^{\mathrm{d}}$, Roland Kays ${ }^{\mathrm{b}, \mathrm{e}}$, Martin C. Wikelski ${ }^{\mathrm{a}, \mathrm{b}}$ \\ a Division of Migration and Immuno-ecology, Max Planck Institute for Ornithology, Radolfzell, Germany \\ ${ }^{\mathrm{b}}$ Smithsonian Tropical Research Institute, Ancon, Panama \\ ${ }^{\mathrm{c}}$ Department of Ecology and Evolutionary Biology, Princeton University, Princeton, NJ, U.S.A. \\ ${ }^{\mathrm{d}}$ Department of Biology, Frostburg State University, Frostburg, MD, U.S.A. \\ e New York State Museum, CEC 3140, Albany, NY, U.S.A
}

\section{Keywords:}

Barro Colorado Island, Panama

Cebus capucinus

habituation

telemetry
In studies of animal behaviour, researchers have long been concerned that their presence may change the conduct of their study subjects. To minimize observer effects, researchers often habituate their study animals. The premise of this method is that, with sufficient neutral exposure, animals will stop reacting to humans. While numerous studies demonstrate that negative responses to humans decrease over time, the fact that an animal does not flee from or behave aggressively towards observers cannot be taken as evidence that it is not altering its behaviour in other, more subtle ways. Because remotely monitoring the behaviour of wild animals is difficult, it has not been possible to answer the critical question: do habituated animals change their behaviour when researchers are present? Here, we use data from an automated radiotelemetry system that remotely monitored the movement and activity of radiocollared animals to test whether observers affected the behaviour of seven habituated white-faced capuchins, Cebus capucinus. We found no evidence that observers influenced the ranging behaviour or activity patterns of their study subjects. Capuchins did not move faster, stop to rest less frequently, or display higher levels of activity when they were being followed compared to when they were alone. It has been suggested that researchers may embolden habituated study subjects, artificially increasing their relative dominance, but we found no relationship between observer presence and proximity to neighbouring social groups. Although it remains possible that observer effects existed but were too subtle to be detected with the remote sensing technology we used, the results of this study nevertheless provide reassuring evidence that humans can observe habituated wild animals without overly influencing the animals' activity and movement patterns.

\section{BACIKGROUND}

Realizing that the normal behavior of wild animals might be completely distorted by the presence of an observer, attempts were made to observe animals with a minimum of disturbance. It was desired to observe the[ir] activity... as it would have occurred had there been no observer present.

Carpenter (1934, page 22)

Studying animals in their natural habitat is critical for understanding their biology and behaviour (e.g. Rattenborg et al. 2008). However, wild animals often react strongly to humans, either fleeing, or producing threats or alarm calls in response to observer

\footnotetext{
* Correspondence: M. C. Crofoot, Smithsonian Tropical Research Institute, Unit 9100, Box 0948, DPO, AA 34002-9998, U.S.A.

E-mail address: crofootm@si.edu (M.C. Crofoot).
}

presence (Williamson \& Feistner 2003; Blom et al. 2004; Bertolani $\&$ Boesch 2008; Aguiar \& Moro-Rios 2009). These negative reactions present a problem for researchers trying to study animal behaviour under natural conditions. One solution to this problem has been to hide researchers from view using natural or constructed blinds, or to remove researchers entirely and use radiotelemetry, camera traps or other remote data collection methods (Martin \& Bateson 1986; Lehner 1996; Setchell \& Curtis 2003). The first of these approaches limits observers to a fixed location, decreasing the range of behaviours that can be observed, while the second, although quite effective for certain types of studies, cannot provide the detailed behavioural data gained through direct observation (Aguiar \& Moro-Rios 2009).

Since Carpenter (1934) first proposed that, with sufficient 'neutral exposure', animals would become accustomed to and eventually ignore human observers, habituation has been an important alternate method for minimizing observer effects in 
studies of wild animals. It has been widely used in field studies of species ranging from primates (Williamson \& Feistner 2003; Aguiar \& Moro-Rios 2009), to carnivores (Potos flavus: Kays \& Gittleman 2001; Nasua nasua: Hirsch 2007; Crocuta crocuta: Hofer \& East 2008; Suricata suricatta: Clutton-Brock et al. 1999; Mungos mungo: Gilchrist 2008) to cetaceans (Tursiops sp.: Connor \& Smolker 1985), to birds (Megadyptes antipodes: Ellenberg et al. 2009; Spheniscus magellanicus: Walker et al. 2006), and has played a crucial role in elucidating the socio-ecology of many of these species.

Despite its widespread use, concerns remain about the reliability of data collected by observing habituated animals. Although few have explicitly addressed the issue, researchers generally acknowledge that observer presence may influence certain aspects of animal behaviour including, for example, predation rates (Isbell \& Young 1993) and the frequency or outcome of intergroup interactions (Rasmussen 1991; Zinner et al. 2001). These effects are generally attributed to the impact of the human observer on the behaviour of unhabituated neighbours or predators, rather than to changes in the behaviour of the habituated individuals themselves. However, some contend that observer effects may be much more widespread and significant than we usually acknowledge. As Martin \& Bateson (1986) stress in their influential book on methods in animal behaviour research, habituation is 'a stratagem that generally seems to work well...[but]the impression that wellhabituated subjects are not affected by the observer's presence is difficult to verify and should be treated with some skepticism'.

Numerous studies documenting the habituation process demonstrate that overt reactions to human observers such as fleeing, screaming and performing threat or alarm vocalizations or aggressive displays decrease over time (e.g. Grieser Johns 1996; Van Krunkelsvewn et al. 1999; Blom et al. 2004; Bertolani \& Boesch 2008; Jack et al. 2008). Other measures of behaviour, including day range (Rasmussen 1998; Cipolletta 2004) and activity budget (Williamson \& Feistner 2003) also tend to change as the amount of time an animal has been under observation increases. Such patterns are taken as evidence of habituation, and scientists assume that once these obvious behavioural responses to human presence have ceased, the study animals have returned to their normal patterns of daily activity. However, research on observer effects in studies of captive animals suggests that human observers can influence the behaviour of their study subjects in more subtle ways (Caine 1989; Wade et al. 2005; Baker \& McGuffin 2007). For example, a study of captive tamarins demonstrated that even after animals ceased to respond to observers with overt antipredator behaviours, the presence of a human still had a measureable impact on their activity patterns (Caine 1989). Thus, the key question is not whether negative reactions to human observers decrease with time, but instead whether habituated study animals behave differently when they are being observed than when they are alone.

New, remote monitoring technologies capable of measuring behaviour without relying on direct human observation make it possible to convincingly assess, for the first time, the importance of observer effects on the behaviour of habituated wild animals. In this paper, we use data from an automated radiotracking system to test whether habituated capuchin monkeys altered their behaviour when a human was present. We predicted that if observer presence disturbed the apparently habituated capuchins, they would try to avoid researchers by travelling faster, stopping less frequently, and exhibiting increased activity levels. We also tested whether human observers increased the relative dominance of habituated capuchin groups. If this was the case, we predicted that the study animals would be more likely to approach and spend time in close proximity to neighbouring groups when researchers were present.

\section{METHODS}

We used an Automated Radio Telemetry System (ARTS) to monitor the movements of seven radiocollared white-faced capuchin monkeys, Cebus capucinus, living on Barro Colorado Island (BCI), Panama. Barro Colorado, the site of a Smithsonian Tropical Research Institute field station, is a $\mathbf{1 5 0 0}$ ha island of semi-deciduous lowland forest that was isolated from the mainland in 1914 when the Chagres River was dammed to create Lake Gatun and the Panama Canal. It is home to a population of 250-300 capuchin monkeys in approximately 20 different social groups (Mitchell 1989; M. C. Crofoot, unpublished data).

Between 30 July and 6 August 2004, seven capuchins belonging to four neighbouring social groups (Table 1, Fig. 1) were captured and fitted with radiocollars. These individuals were chemically immobilized with Telazol ${ }^{\circledR}(50 \mathrm{mg} / \mathrm{ml}$ of tiletamine hydrochloride, $50 \mathrm{mg} / \mathrm{ml}$ of zolazepam hydrochloride; Fort Dodge Animal Health, Fort Dodge, IA, U.S.A.), a non-narcotic, nonbarbiturate injectable anaesthetic, delivered via a Pneu-Dart ${ }^{\mathrm{TM}} \mathrm{CO}_{2}$ gun (Pneu-Dart, Williamsburg, PA, U.S.A.). Outstretched hammocks were positioned below the sedated animals to catch them as they became drowsy and lost their grip (see Crofoot et al. 2009 for a full description of capture methods, including drug doses, physiological parameters and recovery times). Once animals were on the ground and their heart rate, respiration and temperature had been assured, we fit each of them with a tubular nylon radiocollar (Advanced Telemetry Systems, Isanti, MN, U.S.A.). The collars weighed $41 \mathrm{~g}$, which was less than $2 \%$ of the body weight of the smallest individual we captured, and well within the recommended limit of $5 \%$ of a subject's body mass (Macdonald \& Amlaner 1980). Initially, the capuchins responded strongly to the radiocollars, pulling at them and chewing on the antennae. However, they habituated quickly these behaviours were greatly reduced after only a few hours and had disappeared entirely within 2 weeks (Crofoot et al. 2009).

We tracked seven capuchins using the ARTS from November 2004 through April 2005. In addition, we conducted regular behavioural observations (six 3-hour follows per group, per month) from June 2004 through September 2005. During these follows, we recorded the occurrence of researcher-directed threats on an allevents basis. All research received clearance from the Harvard University Institutional Animal Care and Use Committee (assurance no. A-3593-1)

Study animals experienced 5 months of regular contact with human observers before we started tracking them with the ARTS by which time they appeared to be well habituated to the presence of researchers. To test whether rates of observer-directed threats had stabilized before the start of systematic data collection (November 2004), we used a standard least squares regression to investigate the relationship between study month and the frequency with which capuchins in each group threatened us during behavioural follows. We included group identity and a group*month of study interaction term in the model to control for possible differences among groups.

Table 1

Study group size and age/sex class of radiocollared individuals

\begin{tabular}{lllll}
\hline Group & Group size & Animal ID & Sex & Age \\
\hline TB & 10 & 51 & F & A \\
BLT & 9 & 52 & M & SA \\
& & 53 & F & A \\
Top & \multirow{2}{*}{16} & 54 & F & A \\
& & 55 & M & A \\
BL12 & 25 & 57 & F & A \\
& & 58 & M & A \\
\hline
\end{tabular}




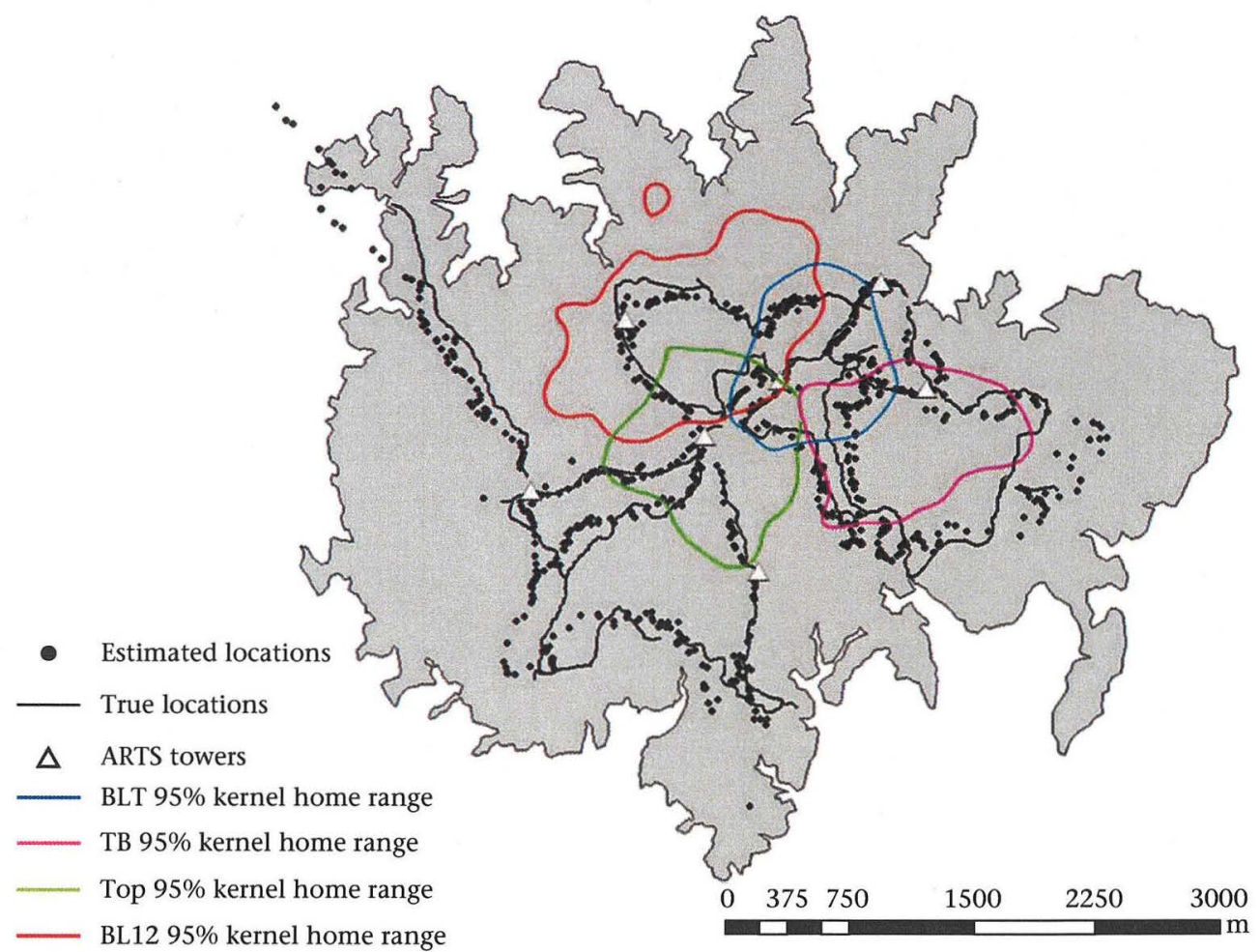

Figure 1. Location of study group home ranges (95\% fixed kernel estimates based on 6 months of tracking data) in relation to the results of a test-walk conducted to determine the accuracy of the Automated Radio Telemetry System (ARTS). These four capuchin groups were chosen for study, out of $\sim 20$ groups on the island, because they lived in the central portion of the island where ARTS coverage was highest and location error was lowest ( $<50 \mathrm{~m}$; Crofoot et al. 2008).

To remotely monitor capuchin behaviour, we used ARTS, a multiuser infrastructure designed to continuously and simultaneously track the movements of multiple radiocollared study animals (see http://www.princeton.edu/ wikelski/research/index. htm for additional information). ARTS consists of seven $40 \mathrm{~m}$ radio towers, each topped with a fixed array of six directional antennas and connected to an automated receiving unit (for a detailed description of the receiving units, see Larkin et al. 1996). The automated receivers are synchronized to scan through a list of radio frequencies corresponding to the transmitters worn by study animals. They record the relative strength of the radio signals across the fixed antenna arrays and transmit these data in real time via a wireless network (FreeWave, www.freewave.com) to a server at the Smithsonian Tropical Research Institute on Barro Colorado Island, where they are automatically loaded into a web-accessible PostgreSQL database. The relative signal strengths are converted into bearings within the database, and these bearings are smoothed using signal processing software (PV-Wave, Visual Numerices, Inc., Houston, TX, U.S.A.) to reduce noise. The system records one bearing every $1.5 \mathrm{~s}$, and takes 10 bearings for each frequency before continuing to the next frequency on the search list. These 10 bearing estimates are then used to triangulate a single location estimate using an Andrew's M-estimator (Lenth 1981a, b) implemented in the software program LOAS (Sallee 2004). ARTS accuracy varies depending on the location of the transmitter on the island, but average linear error within the home ranges of the study groups was $42 \mathrm{~m}$ ( $\mathrm{SD}=34$; see Fig. 1$)$.

For this study, the ARTS was programmed to estimate the location of each study animal every $10 \mathrm{~min}$. From these data we calculated velocity as the distance moved between successive location estimates divided by the amount of time (in minutes) elapsed between these measures. Animals were considered 'stopped' if they moved less than $10 \mathrm{~m}$ in a 10 min sampling period. Given the limited spatial resolution of the ARTS, this definition will yield both false negatives and false positives, but it is not biased by the presence or absence of human observers and thus should allow us to compare the relative frequency of stops in these two conditions. To investigate patterns of interaction between adjacent social groups, we calculated the minimum distance between the focal individual and radiocollared animals in neighbouring groups during each sampling period. Finally, we calculated the percentage of each sampling period that the animal was active based on the $\Delta$ signal strength between successive ARTS measurements (see Lambert et al. 2009 for a description of the methods). When the orientation of a radiocollar is changed, the polarization of the antenna is also altered, changing the strength of the radio signal received by the ARTS system. Thus, when a radiocollared animal was moving, the strength of the signals received by the ARTS was more variable than when the animal was still.

To assess the effect of observer presence on capuchin monkey behaviour, we selected ARTS data from periods of time when a radiocollared individual's group was under observation to a sample of ARTS data, matched for time of day and duration, from the nearest day when no human observer was present. On these unobserved days, researchers were still present in the forest, but were not following the group in question. Because of the large size of capuchin home ranges (100 ha; Crofoot 2007) and the dense nature of the forest on $\mathrm{BCl}$, we feel it is unlikely that capuchins in unobserved groups were aware of, or responding to, researchers working in other parts of the island. To normalize the data, we applied a $\log$ transformation (velocity and nearest-neighbour distance) or an arcsine square-root transformation (percentage of time active and percentage of time stopped). We then used a MANOVA to determine whether the capuchins' behaviour 
differed significantly when they were being followed and when they were alone. We controlled for the period of the study (first half (early) versus second half (late)) because we expected the level of habituation shown by the focal individuals to increase over the course of the study, and individual animal identifiers were included in the model as random effects to account for potential differences in individual responses. We first ran saturated models, and then removed all nonsignificant interaction terms. We then used univariate mixed linear models to determine which dependent variables were responsible for significant results in the MANOVA. Interaction terms were examined, and nonsignificant interactions removed.

\section{RESULTS}

Rates of observer-directed threats by capuchins differed between study groups, but did not decrease over the course of the study (see Table 2). In fact, in one social group, rates of observerdirected threats increased (TB group, slope $=0.059, t=2.58$, $P=0.015$ ), but the group*month of study interaction term was not significant in the overall model (Table 2).

Observer presence did not significantly affect any of the behaviours we investigated (see Table 3 ). None of the interactions terms were significant in the MANOVA and thus they were removed from the model. MANOVA results indicated that the behaviour of focal individuals differed between the first and second half of the study (Wilk's $\lambda=0.91, P=0.0041$ ). However, observer presence did significantly affect capuchin behaviour (Wilk's $\lambda=0.95, P=0.1358$ ). Mixed linear models revealed that individuals were significantly more active during the latter half of the study $\left(F_{1,153}=14.99, P=0.0002\right.$; Table 3$)$.

\section{DISCUSSION}

This study provides the first direct evidence that humans can observe habituated wild animals without changing the animals' activity and movement patterns. One concern that is frequently raised about observational studies of wild animals is that researchers may unintentionally 'push' their study subjects (e.g. Williamson \& Feistner 2003). If animals travel faster and rest less frequently in an attempt to escape their human pursuers, this may impose substantial energetic costs. We found no evidence that human observers pushed habituated capuchin monkeys. Capuchins did not travel faster, stop less frequently, or spend more time active when they were being followed by researchers than when they were alone.

The presence of human observers also did not appear to artificially increase the dominance of the habituated study groups. Capuchins in this population spent $6-8 \%$ of their time in close proximity to neighbouring groups ( $\leq 150 \mathrm{~m}$; M. C. Crofoot, unpublished data), and regularly engaged in aggressive intergroup interactions (on average, one aggressive interaction every 3 days; Crofoot 2007) which had important effects on their foraging success (Crofoot 2008). Despite the potential benefits of increased intergroup dominance, capuchins in this study were not more likely to approach neighbouring groups when being observed, as

Table 2

Output from a least squares regression of observer-directed threat rate versus month of study and group identity

\begin{tabular}{lllll}
\hline Variable & $d f$ & Sum of squares & $F$ ratio & $P$ \\
\hline Group & 3 & 1.077 & 6.900 & 0.001 \\
Month of study & 1 & 0.112 & 2.166 & 0.151 \\
Group*month of study & 3 & 0.380 & 2.435 & 0.084 \\
\hline
\end{tabular}

would be expected if the presence of humans emboldened them. Ours, however, was not a strong test of the emboldening hypothesis because all groups for which remote monitoring data was available were also regularly being observed by researchers and thus were well habituated. Any emboldening effect should be most pronounced in the interactions between study groups and their unhabituated neighbours. Thus, to properly test the hypothesis, both the movements of study groups and adjacent, unhabituated groups should be monitored simultaneously.

By traditional measures, all four groups of capuchins in this study were fully habituated. While capuchins regularly threatened and fled from human observers when we first started observing them (June 2004; M.C.C., personal observation), these behaviours had largely ceased by the start of systematic data collection (November 2004) and we found no decrease in the rate of observerdirected threats over the course of our study (November 2004-April 2005). Surprisingly, one capuchin group (TB group) significantly increased their rate of observer-directed threats during the study period. These threats were not accompanied by any other signs of fear and were often performed at distances of $1-2 \mathrm{~m}$ from the observer (M.C.C., personal observation). Capuchins regularly threaten a wide range of innocuous objects in their habitat, including inanimate objects like rocks, perhaps as a strategy for redirecting aggression or diffusing social tension (Perry 1996a, b, 1997). Thus, we think that this pattern may, counterintuitively, reflect increasing comfort with and habituation to the researchers.

We did find a difference in overall activity level between the first and second halves of the study; the capuchins were more active during the second half. Although it is possible that this was an observer effect and a sign of incomplete habituation, the fact that the difference was not in the predicted direction leads us to conclude that it was more likely due to seasonal differences in food availability. The early months of the study (November-January) correspond to the season of food shortage on Barro Colorado Island when many animal species may reduce activity levels in an attempt to maintain a positive energy balance (Foster 1982; Leigh, 1999). The later months (February-April), in contrast, are marked by increasing resource availability (Leigh 1999).

The results of this study support scientists' impressions that well-habituated animals are not overly affected by the presence of observers: researchers did not alter the behaviour of the habituated capuchins in this study in ways that could be measured using an automated radio telemetry system. This is not to say that no

Table 3

Output from univariate linear mixed models of average velocity $(\mathrm{m} / \mathrm{min})$, percentage of time spent stopped, percentage of time spent active and nearest-neighbour distance versus observer presence (present/absent) and study period (early/late)

\begin{tabular}{|c|c|c|c|c|c|}
\hline & $\begin{array}{l}\text { Present/early } \\
(\text { Mean } \pm \text { SD) }\end{array}$ & $\begin{array}{l}\text { Absent/late } \\
(\text { Mean } \pm \text { SD) }\end{array}$ & $d f$ & $F$ ratio & $P$ \\
\hline \multicolumn{6}{|c|}{ Average velocity (m/min) } \\
\hline Observer presence & $6.12 \pm 1.39$ & $6.33 \pm 0.99$ & 12 & 0.63 & 0.44 \\
\hline Study period & $6.22 \pm 1.11$ & $6.30 \pm 1.18$ & 153 & 0.17 & 0.68 \\
\hline \multicolumn{6}{|l|}{ \% Time stopped } \\
\hline Observer presence & $6.74 \pm 3.01$ & $7.98 \pm 3.27$ & 12 & 1.3 & 0.28 \\
\hline Study period & $7.28 \pm 3.82$ & $7.16 \pm 4.50$ & 153 & 0.14 & 0.71 \\
\hline \multicolumn{6}{|l|}{ \% Time active } \\
\hline Observer presence & $55.61 \pm 5.72$ & $57.17 \pm 5.58$ & 12 & 0.11 & 0.75 \\
\hline Study period & $52.87 \pm 5.77$ & $60.19 \pm 6.12$ & 153 & 14.99 & $<0.01$ \\
\hline \multicolumn{6}{|c|}{ Nearest-neighbour distance (m) } \\
\hline Observer presence & $729.99 \pm 48.49$ & $674.75 \pm 62.31$ & 12 & 2.61 & 0.13 \\
\hline Study period & $684.01 \pm 74.26$ & $714.74 \pm 95.25$ & 153 & 1.06 & 0.31 \\
\hline
\end{tabular}


observer effect existed, only that the magnitude of the effect must be smaller than that of a wide range of factors including time of day, season, group membership and proximity to neighbours, which all had a measurable impact on capuchin activity patterns and movements in this data set (Crofoot 2008). It remains possible that subtle observer effects occurred that we were not able to distinguish using the relatively crude measure of activity produced by automated radio telemetry. While observer presence did not influence the percentage of time that capuchins were active, they may have engaged in different types of activities when they were being observed. For example, if capuchins spend more time being vigilant when researchers are present, at the expense of other activities such as feeding or resting, this may have very important ramifications. Advances in remote sensing, particularly the use of 3D accelerometers to discriminate between activity categories (Yoda et al. 2001; Watanabe et al. 2005), may allow us to distinguish such finer-scale differences in future studies.

Habituation is a key tool for studying the behaviour of a wide range of wild animals in their natural habitat. Arboreal and/or group-living animals seem to respond particularly well to habituation efforts, whereas attempts to habituate terrestrial and/or solitary species have been slower and less successful (Aguiar \& Moro-Rios 2009). Given their lifestyle, protection from hunting pressure and the frequency with which they encounter human researchers, it is perhaps not surprising that the capuchin monkeys on Barro Colorado Island, Panama do not respond strongly to the presence of human observers. An important future step will be to investigate whether these results hold true for other species, especially solitary, terrestrial species where observer effects are expected to be larger.

\section{Acknowledgments}

We thank the Autoridad Nacional del Ambiente (ANAM) and the government of Panama for permission to conduct research in Panama, and the Smithsonian Tropical Research Institute, and especially Oris Acevedo for logistical support. Technical support was provided by the Automated Radio Telemetry System Initiative, particularly Daniel Obando, Pablo Flores, Alejandro Ortega and Kevin Sallee. We also thank Vilma Fernandez for her help collecting data, Michelle Brown, Robyn Hoing, Jennifer Boothby, Robert Horan, Vilma Fernandez and George Middleton for help with darting, Nicanor Obaldia, DVM, Claudia Brandariz, DVM and Terry Norton, DVM for veterinary support and Ben Hirsch, Scott Mangan, Ian Gilby, Susy Cote, Michelle Brown and two anonymous referees for their comments on this paper. Financial support for this work was provided by the Frederik Sheldon Travel Grant, the American Society of Primatologists, the Smithsonian Tropical Research Institute, Sigma Xi, the Department of Biology at Armstrong Atlantic State University, and the Program in Biological Anthropology, Harvard University. Required permits for the work described in this paper were obtained from the Autoridad Nacional del Ambiente, Panama, and the Smithsonian Tropical Research Institute. All research complied with the laws of the Republic of Panama and the United States of America.

\section{References}

Aguiar, L. M. \& Moro-Rios, R. F. 2009. The direct observational method and possibilities for Neotropical carnivores: an invitation for the rescue of a classical method spread over the primatology. Zoologia, 26, 587-593.

Baker, R. L. \& McGuffin, M. A. 2007. Technique and observer presence affect reporting of behavior of damselfly larvae. Journal of the North American Benthological Society, 26, 145-151.

Bertolani, P. \& Boesch, C. 2008. Habituation of wild chimpanzees (Pan troglodytes) of the South group at Tai Forest, Cote d'Ivoire: empirical measure of progress. Folia Primatologica, 79, 162-171.
Blom, A., Cipolletta, C., Brunsting, A. M. H. \& Prins, H. H. T. 2004. Behavioral responses of gorillas to habituation in the Dzanga-Ndoki National Park, Central African Republic. International Journal of Primatology, 25, 179-196.

Caine, N. G. 1989. Unrecognized anti-predator behaviour can bias observational data. Animal Behaviour, 39, 195-197.

Carpenter, C. R. 1934. A field study of the behavioral and social relations of howling monkeys (Alouatta palliata). Comparative Psychology Monographs, 10, 1-168.

Cipolletta, C. 2004. Effects of group dynamics and diet on the ranging patterns of a western gorilla group (Gorilla gorilla gorilla) at Bai Hokou, Central African Republic. American Journal of Primatology, 64, 193-205.

Clutton-Brock, T. H., Maccoll, A., Chadwick, P., Gaynor, D., Kansky, R. \& Skinner, J. D. 1999. Reproduction and survival of suricates (Suricata suricatta) in the southern Kalahari. African Journal of Ecology, 37, 69-80.

Connor, R. C. \& Smolker, R. S. 1985. Habituated dolphins (Tursiops sp) in Western Australia. Journal of Mammalogy, 66, 398-400.

Crofoot, M. C. 2007. Mating and feeding competition in white-faced capuchins (Cebus capucinus): the importance of short- and long-term strategies. Behaviour, 144, 1473-1495.

Crofoot, M. C. 2008. Intergroup competition in white-faced capuchin monkeys (Cebus capucinus): automated radio-telemetry reveals how intergroup relationships shape space-use and foraging success. Ph.D. thesis, Harvard University.

Crofoot, M. C., Gilby, I. C., Wikelski, M. C. \& Kays, R. W. 2008. Interaction location outweighs the competitive advantage of numerical superiority in Cebus capucinus intergroup contests. Proceedings of the National Academy of Sciences, U.S.A., 105, 577-581.

Crofoot, M. C., Norton, T. M., Lessnau, R. G., Viner, T. C., Chen, T. C., Mazzaro, L. M. \& Yabsley, M. J. 2009. Field anesthesia and health assessment of free ranging white-faced capuchin monkeys (Cebus capucinus) in Panama. International Journal of Primatology, 30, 125-141.

Ellenberg, U., Mattern, T. \& Seddon, P. J. 2009. Habituation potential of yelloweyed penguins depends on sex, character and previous experience with humans. Animal Behaviour, 77, 289-296.

Foster, R. B. 1982. The seasonal rhythm of fruitfall on Barro Colorado Island. In: The Ecology of a Tropical Forest: Seasonal Rhythms and Long-term Changes (Ed. by E. G. J. Leigh, A. S. Rand \& D. M. Windsor), pp. 151-172. Washington, D.C.: Smithsonian Institution Press.

Gilchrist, J. S. 2008. Aggressive monopolization of mobile carers by young of a cooperative breeder. Proceedings of the Royal Society B, 275, 2491-2498.

Grieser Jolnns, B. 1996. Responses of chimpanzees to habituation and tourism in the Kibale Forest, Uganda. Biological Conservation, 78, 257-262.

Hirsch, B. T. 2007. Spoiled brats: is extreme juvenile agonism in ring-tailed coatis (Nasua nasua) dominance or tolerated aggression? Ethology, 113, 446-456.

Hofer, H. \& East, M. L. 2008. Siblicide in Serengeti spotted hyenas: a long-term study of maternal input and cub survival. Behavioral Ecology and Sociobiology, 62, 341-351.

Isbell, L. A. \& Young, T. P. 1993. Human presence reduces leopard predation in a free-ranging population of vervet monkeys (Cercopithecus aethiops). Animal Behaviour, 45, 1233-1235.

Jack, K. M., Lenz, B. B., Healan, E., Rudman, S., Schoof, V. A. M. \& Fedigan, L. 2008. The effects of observer presence on the behavior of Cebus capucinus in Costa Rica. American Journal of Primatology, 70, 490-494.

Kays, R. W. \& Gittleman, J. G. 2001. The social organization of the kinkajou Poto flavus (Procyonidae). Journal of Zoology, 253, 491-504.

Lambert, T. D., Kays, R. W., Jansen, P. A., Aliaga-Rossel, E. \& Wikelski, M. 2009 Nocturnal activity by the primarily diurnal Central American agouti (Dasyprocta punctata) in relation to environmental conditions, resource abundance and predation risk. Journal of Tropical Ecology, 25, 211-215.

Larkin, R. P., Raim, A. \& Diehl, R. H. 1996. Performance of a nonrotating directionfinder for automatic radio tracking. Journal of Field Ornithology, 67, 59-71.

Lehner, P. N. 1996. Handbook of Ethological Methods. Cambridge: Cambridge University Press.

Leigh, E. G. J. 1999. Tropical Forest Ecology: a View from Barro Colorado Island. Oxford: Oxford University Press.

Lenth, R. V. 1981a. On finding the source of a signal. Technometrics, 23, 149-154.

Lenth, R. V. 1981b. Robust measures of location for directional-data. Technometrics, 23, 77-81.

Macdonald, D. W. \& Amlaner, C. J. 1980. A practical guide to radio tracking. In: A Handbook on Biotelemetry and Radio Tracking (Ed. by C. J. Amlaner \& D. W. MacDonald), pp. 143-159. Oxford: Pergamon Press.

Martin, P. \& Bateson, P. 1986. Measuring Behaviour. Cambridge: Cambridge University Press.

Mitchell, B. 1989. Resources, group behavior, and infant development in whitefaced capuchin monkeys, Cebus capucinus. Ph.D. thesis, University of California, Berkeley.

Perry, S. 1996a. Female-female social relationships in wild white-faced capuchin monkeys, Cebus capucinus. American Journal of Primatology, 40, 167-182.

Perry, S. 1996b. Intergroup encounters in wild white-faced capuchins (Cebus capucinus). International Journal of Primatology, 17, 309-330.

Perry, S. 1997. Male-female social relationships in wild white-faced capuchins (Cebus capucinus). Behaviour, 134, 477-510.

Rasmussen, D. R. 1991. Observer influence on range use of Macaca arctoides after 14 years of observation? Laboratory Primate Newsletter, 30, 6-11.

Rasmussen, D. R. 1998. Changes in range use of Geoffroy's tamarins (Saguinus geoffroyi) associated with habituation to observers. Folia Primatologica, 69, 153-159. 
Rattenborg, N. C., Voirin, B., Vyssotski, A. L., Kays, R. W., Spoelstra, K. Kuemmeth, F., Heidrich, W. \& Wikelski, M. 2008. Sleeping outside the box: electroencephalographic measures of sleep in sloths inhabiting a rainforest. Biology Letters, 4, 402-405.

Sallee, K. L. 2004. LOAS. Urnasch, Switzerland: Ecological Software Solutions.

Setchell, J. M. \& Curtis, D. J. 2003. Field and Laboratory Methods in Primatology. Cambridge: Cambridge University Press.

Van Krunkelsvewn, E., Dupain, J., van Elsacker, L. \& Verheyen, R. 1999. Habituation of bonobos (Pan paniscus): first reactions to the presence of observers and the evolution of response over time. Folia Primatologica, 70 365-369.

Wade, M. R., Zalucki, M. P. \& Franzmann, B. A. 2005. Influence of observer presence on Pacific damsel bug behavior: who is watching whom? Journal of Insect Behavior, 8, 651-667.
Walker, B. G. Boersma, P. D. \& Wingfield, J. C. 2006. Habituation of adult Magellanic penguins to human visitation as expressed through behavior and corticosterone secretion. Conservation Biology, 20, 146-154.

Watanabe, S., Izawa, M., Kato, A., Ropert-Coudert, Y. \& Naito, Y. 2005. A new technique for monitoring the detailed behaviour of terrestrial animals: a case study with the domestic cat. Applied Animal Behaviour Science, 94, 117-131.

Williamson, E. A. \& Feistner, A. T. C. 2003. Habituating primates: processes, techniques, variables and ethics. In: Field and Laboratory Methods in Primatology (Ed. by J. M. Setchell \& D. J. Curtis), pp. 25-39. New York: Cambridge University Press. Yoda, K., Naito, Y., Sato, K., Takahashi, A., Nishikawa, J., Ropert-Coudert, Y., Kurita, M. \& Le Maho, Y. 2001. A new technique for monitoring the behaviour of free-ranging Adélie penguins. Journal of Experimental Biology, 204, 685-690.

Zinner, D., Hindahl, J. \& Kaumanns, W. 2001. Experimental intergroup encounters in lion-tailed macaques (Macaca silenus). Primate Report, 59, 77-92. 